Research Article

\title{
Effects of the Phytochemical Combination PB123 on Nrf2 Activation, Gene Expression, and the Cholesterol Pathway in HepG2 Cells
}

Brooks M. Hybertson ${ }^{1,2,}{ }^{*}$, Bifeng Gao ${ }^{1,2}$, Joe M. McCord ${ }^{1,2}$

1. Pathways Bioscience, Aurora, CO 80045, USA; E-Mails: brooks.hybertson@cuanschutz.edu; bifeng.gao@cuanschutz.edu; joe.mccord@cuanschutz.edu

2. Department of Medicine, Division of Pulmonary Sciences and Critical Care Medicine, University of Colorado Anschutz Medical Campus, Aurora, CO 80045, USA

* Correspondence: Brooks M. Hybertson; E-Mail: brooks.hybertson@cuanschutz.edu

Academic Editor: Antonios E. Koutelidakis

Special Issue: Effects of Functional Foods on Nutrition, Human Health and Disease Prevention

OBM Integrative and Complementary Medicine Received: September 21, 2021

2022, volume 7 , issue 1

Accepted: January 04, 2022

doi:10.21926/obm.icm.2201002

Published: January 10, 2022

\begin{abstract}
There has been a long history of human usage of the biologically-active phytochemicals in Salvia rosmarinus, Zingiber officinale, and Sophora japonica for health purposes, and we recently reported on a combination of those plant materials as the PB123 dietary supplement. In the present work we extended those studies to evaluate activation of the nuclear factor erythroid 2-related factor 2 ( Nrf2) transcription factor and differential gene expression in cultured HepG2 (hepatocellular carcinoma) cells treated with PB123. We determined transcriptome changes using mRNA-seq methods, and analyzed the affected pathways using Ingenuity Pathway Analysis and BioJupies, indicating that primary effects included increasing the Nrf2 pathway and decreasing the cholesterol biosynthesis pathway. Pretreatment of cultured HepG2 cells with PB123 upregulated Nrf2-dependent cytoprotective genes and increased cellular defenses against cumene hydroperoxide-induced oxidative stress. In contrast, pretreatment of cultured HepG2 cells with PB123 downregulated cholesterol biosynthesis genes and decreased cellular cholesterol levels. These findings support the possible beneficial effects of PB123 as a healthspan-promoting dietary supplement.
\end{abstract}

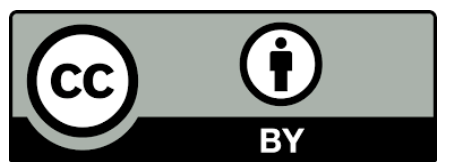

(C) 2022 by the author. This is an open access article distributed under the conditions of the Creative Commons by Attribution License, which permits unrestricted use, distribution, and reproduction in any medium or format, provided the original work is correctly cited. 


\section{Keywords}

Nrf2; KEAP1; oxidative stress; aging; cholesterol; nutrition

\section{Introduction}

Aging and age-related diminishment of the body's antioxidant defenses are associated with a variety of disorders and diseases [1-5]. Dietary composition has significant influence on the body's ability to fight against oxidative stress, which is one of the ways that dietary intake plays a role in healthy aging $[6,7]$. In the past this was largely attributed to direct scavenging of oxidants by compounds consumed in the diet [8-10], but in recent years the focus has shifted to endogenous protection mechanisms and to understanding the health benefits of dietary components based on their ability to activate endogenous defenses, for example by inducing the increased expression of antioxidant enzyme genes [11-14].

Nuclear factor erythroid 2-related factor 2 (Nrf2) is a transcription factor that regulates the gene expression of a wide variety of cytoprotective phase II detoxification enzymes and antioxidant enzymes by engaging the antioxidant-responsive element (ARE) found in the promoter regions of these genes. Based on extensive prior work, the ARE is a promoter element that regulates the expression of many antioxidant, anti-inflammatory, and cytoprotective genes [15-23].

Aging is associated with diminishment of cytoprotective Nrf2 [24-27], which means that agingrelated stressors coincide with a decreased ability to protect against them [27, 28]. Lower nuclear Nrf2 levels have been observed with advanced age in both rats and people [24, 27], along with decreased antioxidant defense and repair capabilities [27]. Naturally long-lived species like the naked mole-rat have been shown to have markedly elevated levels of Nrf2 activation [29]. Total and LDL cholesterol levels tend to increase with age, and concomitantly the risk for atherosclerosis and coronary heart disease also tends to increase with age [30,31]. Notably, previous investigations have indicated that dietary supplementation with ginger, a Nrf2 activator, correlated with decreased cholesterol levels in human subjects [32].

In the present work, we examine effects of the PB123 dietary supplement, a combination of phytochemical compounds from Salvia rosmarinus, Zingiber officinale, and the bioflavonoid luteolin [33-51]. Rosemary (Salvia rosmarinus) has been utilized against a variety of health issues [1], based on reported anti-inflammatory [52], antioxidant [49-51], and antimicrobial benefits [53, 54]. Ginger (Zingiber officinale) is a member of the Zingiberaceae family of plants with over 2500 years of recorded use in traditional therapies, commonly with emphasis on anti-inflammatory, analgesic, and digestive system benefits [55-59]. Luteolin (found in many food and vegetable sources) [60-64] has frequently been used as a dietary supplement based on reported antioxidant [47], neurological [45], and anti-inflammatory benefits [44, 60, 65].

In our prior work, Nrf2-dependent genes were shown to be upregulated in alveolar epithelial cells isolated from HIV-1 transgenic rats after dietary administration of PB123 [66]. In the present work, we studied the ability of the PB123 combination to activate the Nrf2 pathway and upregulate antioxidant, anti-inflammatory, and other cell protective genes in HepG2 cells, and we determined its protection of cultured HepG2 cells against oxidative stress and dyslipidemia. 


\section{Materials and Methods}

\subsection{Materials and Reagents}

Plant extracts: ginger root extract from Zingiber officinalis (standardized to $20 \%$ gingerols) and rosemary extract from Salvia rosmarinus (standardized to $6 \%$ carnosol; $15 \%$ carnosic acid) were obtained from Flavex (Rehlingen, Germany); luteolin (from Sophora japonica, standardized to 98\% luteolin) was obtained from Jiaherb (Pine Brook, NJ, USA). Solvent extracts of PB123 powder were prepared by mixing a 10:5:1 mass ratio of rosemary, ginger, and luteolin powders then extracting the mixed powder $(50 \mathrm{mg} / \mathrm{mL})$ overnight in ethanol and collecting the supernatant [66, 67]. Cell culture: antibiotics and culture media powder were obtained from Thermo Fisher Scientific (Waltham, MA, USA). Reagents and assays: The intracellular lipid staining assay (Steatosis Colorimetric Assay Kit), ERK1/2 inhibitor (PD98059, CAS 167869-21-8), and Nrf2 inhibitor (AEM1, CAS 1030123-90-0) were obtained from Cayman Chemical (Ann Arbor, MI, USA). The cholesterol assay (Cholesterol/Cholesterol Ester-Glo) was obtained from Promega (Promega Corporation, Madison, WI, USA). Cumene hydroperoxide (CAS 80-15-9) and all other reagents were obtained from Sigma-Aldrich (St. Louis, MO, USA).

\subsection{Cell Culture}

For the genomic, lipid, and cytoprotection experiments we used the human hepatocellular carcinoma HepG2 cell line. For Nrf2 activation experiments we used HepG2 cells that had been stably transduced with a Nrf2-dependent firefly luciferase gene construct (HepG2-ARE cells), kindly provided by Dr. S.O. Simmons [68]. HepG2 cells are appropriate for the present work because they exhibit normal Nrf2 activation properties [69], lack Nrf2/KEAP1 mutations, and have previously been shown to be suitable for metabolic studies [70]. The HepG2 and HepG2-ARE cells were cultured and maintained by standard methods as previously described [67]. Cell viability was determined using a cell counting kit-8 (CCK8) assay (Dojindo Molecular Technologies, Inc., Rockville, MD, USA). Briefly, cells were assayed for viability by adding CCK8 solution, incubating at $37^{\circ} \mathrm{C}$, and measuring absorbance at $450 \mathrm{~nm}$ using a microplate spectrophotometer (Bio-Tek, Winooski, VT, USA). Absorbance values were normalized to the readings from vehicle control cells, and the data was presented as viable cells percentage relative to vehicle control cells.

\subsection{Nrf2 Reporter Gene Assays}

The HepG2-ARE promoter/reporter cells were used for assaying Nrf2 activation, measured as relative light units (RLU) as previously described [67]. For synergy experiments, cells were treated with combinations of rosemary, ginger, and luteolin extracts and with the corresponding concentrations of extracts of each individual agent. PB123 synergy was visualized by comparing the Nrf2 activation signal from the PB123 combination with the sum of the signals induced by treatments with the individual ingredient extracts with a range of concentrations of PB123 extract $(1.6,3.2,4.8,6.4,8 \mu \mathrm{g} / \mathrm{mL})$ or with the corresponding amounts of rosemary extract $(1,2,3,4,5$ $\mu \mathrm{g} / \mathrm{mL})$, ginger extract $(0.5,1,1,5,2,2.5 \mu \mathrm{g} / \mathrm{mL})$, and luteolin $(0.1,0.2,0.3,0.4,0.5 \mu \mathrm{g} / \mathrm{mL})$ alone. Combinatorial Nrf2 activation calculations using synergy reference models and data from a 
checkerboard style layout of combinations of rosemary extract $(0-24 \mu \mathrm{g} / \mathrm{mL})$ and ginger extract $(0-$ $12 \mu \mathrm{g} / \mathrm{mL}$ ) were performed using calculation tools at synergyfinder.org.

\subsection{Gene Expression Assays}

\subsubsection{Cell Culture and RNA Isolation}

HepG2 cells were treated for $16 \mathrm{~h}$ in $24-$ well plates with 0 (vehicle control) or $12 \mu \mathrm{g} / \mathrm{mL}$ PB123 (as an extract of $50 \mathrm{mg} / \mathrm{mL}$ in $100 \%$ ethanol), with 4 biological replicates per treatment group. The cell culture and RNA isolation was performed as previously described [67]. Briefly, after the treatment period the total RNA was isolated from the cells using Trizol, then purified using Qiagen RNeasy clean-up columns (Qiagen Inc., Valencia, CA, USA). The concentration of RNA in each sample was measured using absorbance at $260 \mathrm{~nm}$ (A260) with a NanoDrop spectrophotometer (Thermo Fisher Scientific, Waltham, MA, USA). The RNA integrity in the samples was determined using Agilent TapeStation 4200 (Agilent, Santa Clara, CA, USA) at the University of Colorado Genomics and Microarray Core facility.

\subsection{2 mRNA-seq Assays}

mRNA-seq Library Preparation. Samples containing 10-100 ng of total RNA were used to prepare the Illumina NGS libraries according to manufacturer's instructions for the NuGEN Universal Plus mRNA-Seq (Tecan Genomics, Redwood City, CA, USA). In this method, polyA selection is used to isolate mRNA from total RNA, which is then fragmented and primed for creation of double-stranded cDNA fragments, which are then amplified, size-selected, and purified for cluster generation.

Sequencing. The mRNA template libraries were then sequenced as paired end $150 \mathrm{bp}$ reads on the Illumina NovaSeq 6000 (Illumina, San Diego, CA, USA) at the University of Colorado Genomics and Microarray Core facility (Aurora, CO, USA). We sequenced at a depth that provides $\sim 40 \mathrm{M} 2$ X150 bases reads per sample.

mRNA-seq Profiling. The sequencing data was processed for differential gene expression as previously described [67]. The computational pipeline for analyzing the derived sequences utilized GSNAP [71], Cufflinks [72], and R for sequence alignment and determination of differential gene expression [73]. In short, GSNAP was used to map the generated reads to the human genome (GRCH38) [71], Cufflinks was used to derived expression (FPKM) [72], and R was used to analyze differential gene expression with ANOVA, with a false discovery rate (FDR) $<0.05$ as the cutoff. The transcriptomic data was examined by pathway analysis using Ingenuity Pathway Analysis (Qiagen, Germantown, MD, USA). For further profiling, the raw sequencing data was also processed using Biojupies $([74,75])$ to identify which pathways of interest were modified by PB123.

\subsection{Protein Assays}

The Human HMOX1 PicoKine ELISA Kit (Boster Biological Technology, Pleasanton, CA, USA) was used to determine heme oxygenase-1 (HMOX1) protein levels in HepG2 cell lysates according to the manufacturer's instructions as previously described [67]. Total protein in the lysates was measured using the method of Lowry [76]. 


\subsection{Total Cholesterol Assays}

The total cholesterol level in cultured HepG2 cells was measured using a chemiluminescent enzymatic assay kit according to manufacturer's instructions (Cholesterol/Cholesterol Ester-Glo ${ }^{\text {TM }}$ Assay kit, Promega, Madison, WI). Briefly, after $24 \mathrm{hr}$ of treatment with PB123, the medium was removed and the HepG2 cells were washed 2x with PBS then lysed using the Cholesterol Lysis Solution. Cell lysate aliquots $(50 \mu \mathrm{l})$ were loaded onto a white, opaque 96 -well plate along with cholesterol standards of known concentration, $50 \mu \mathrm{L}$ of Cholesterol Detection Reagent with Esterase enzyme reagent was added to each well and incubated at room temperature for 1 hour, then luminescence from each well was measured using a platereader luminometer.

\subsection{Intracellular Lipid Assays}

The intracellular lipid level in cultured HepG2 cells was measured using an Oil Red O stain based assay kit according to manufacturer's instructions (Steatosis Colorimetric Assay Kit, Cayman Chemical, Ann Arbor, MI). Briefly, HepG2 cells were treated for $24 \mathrm{~h}$ with 0, 5, or $12 \mu \mathrm{g} / \mathrm{mL}$ PB123, then stained with Oil Red $\mathrm{O}$, lysed, and dye extracted using solutions in the Steatosis Colorimetric Assay Kit, followed by measurement of the extracted Oil Red O dye by absorbance at $492 \mathrm{~nm}$ using the platereader to determine relative intracellular lipid level.

\subsection{Cytoprotection Assays}

To evaluate protective effects against oxidative stress, HepG2 cells were pretreated with PB123, with or without ERK1/2 inhibition by PD98059, and then challenged with cumene hydroperoxide (CH) as previously described [67]. Cytotoxic effects caused by $\mathrm{CH}$ were determined by measuring cell viability using CCK8 assay as described above.

\subsection{Statistical Analysis}

Data are presented as the mean \pm SEM (standard error of the mean) of multiple replicates. Significance of observed differences in the means were evaluated by one-way ANOVA and Tukey's multiple comparisons testing or by Student's $t$ test for unpaired data using Prism 9 software (GraphPad Software, version 9.3.0, San Diego, CA, USA). A $p$ value $<0.05$ was considered statistically significant.

\section{Results}

\subsection{Nrf2 Activation and Synergy}

\subsubsection{Nrf2 Activation}

First PB123 was determined to be nontoxic to HepG2 cells in the $0-50 \mu \mathrm{g} / \mathrm{mL}$ range, which exceeded the concentrations used in the rest of the study (Figure 1A), by measuring cell viability. Using the HepG2 cell line stably transduced with an ARE-promoter/luciferase-reporter construct [68], we determined that PB123 activates Nrf2 in a dose-dependent manner (Figure 1B). As expected, addition of the Nrf2-inhibitor AEM1 (0.5-5 $\mu \mathrm{M})$ dose-dependently attenuated the Nrf2 activation $(\mathrm{p}<0.05)$ by PB123 $(10 \mu \mathrm{g} / \mathrm{mL})$ (Figure 2$)$. 

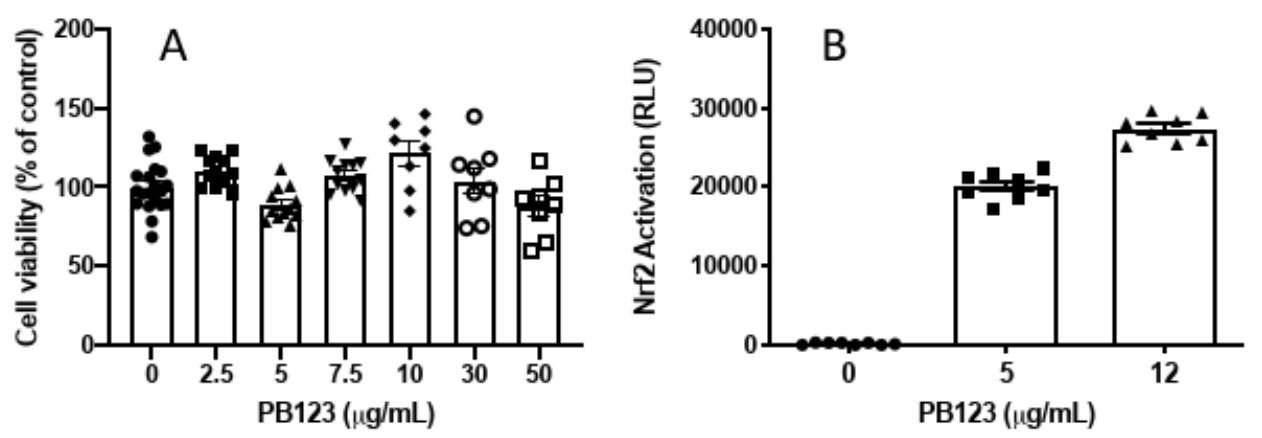

Figure 1 Effect of PB123 treatment on HepG2 cells. (A) PB123 was not toxic to HepG2 cells, measured by treating the cells for $24 \mathrm{~h}$ with PB123 then determining cell viability by CCK8 assay. (B) PB123 activated Nrf2 in HepG2-ARE cells in a dose-dependent manner $(p<0.05)$ by 5 and $12 \mu \mathrm{g} / \mathrm{mL}$ PB123.

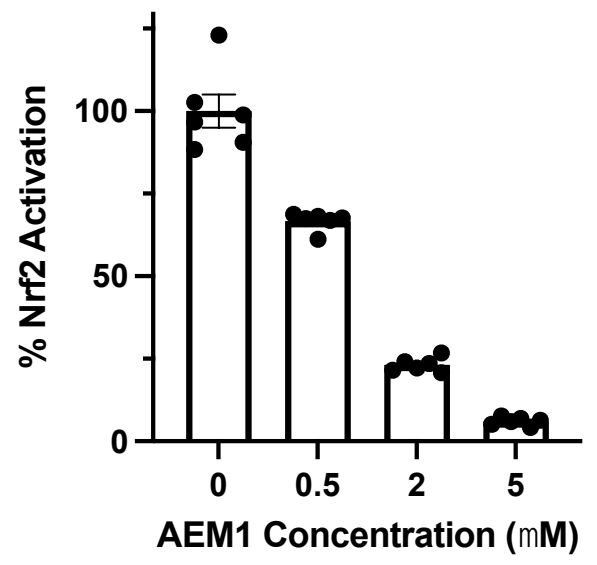

Figure 2 The Nrf2-inhibitor AEM1 dose-dependently blocked Nrf2 activation $(p<0.05)$ induced in HepG2-ARE cells by treatment with PB123 $(10 \mu \mathrm{g} / \mathrm{mL})$.

\subsubsection{Synergy}

Using the HepG2 cell line stably transduced with the ARE-promoter/luciferase-reporter [68], we found that the rosemary, ginger, and luteolin in PB123 combine synergistically for Nrf2 transcription factor pathway activation, with the most notable synergy observed between combinations of rosemary and ginger extracts. To model and visualize the synergy observed with rosemary and ginger for Nrf2 activation, we measured Nrf2 activation in HepG2-ARE cells with checkerboard combinations of rosemary and ginger extract concentrations and then used the Zero Interaction Potency (ZIP) and Loewe synergy. Both the (A) ZIP and (B) Loewe additive effect reference synergy models showed strongly positive synergy scores (synergyfinder.org) (Figure 3). 

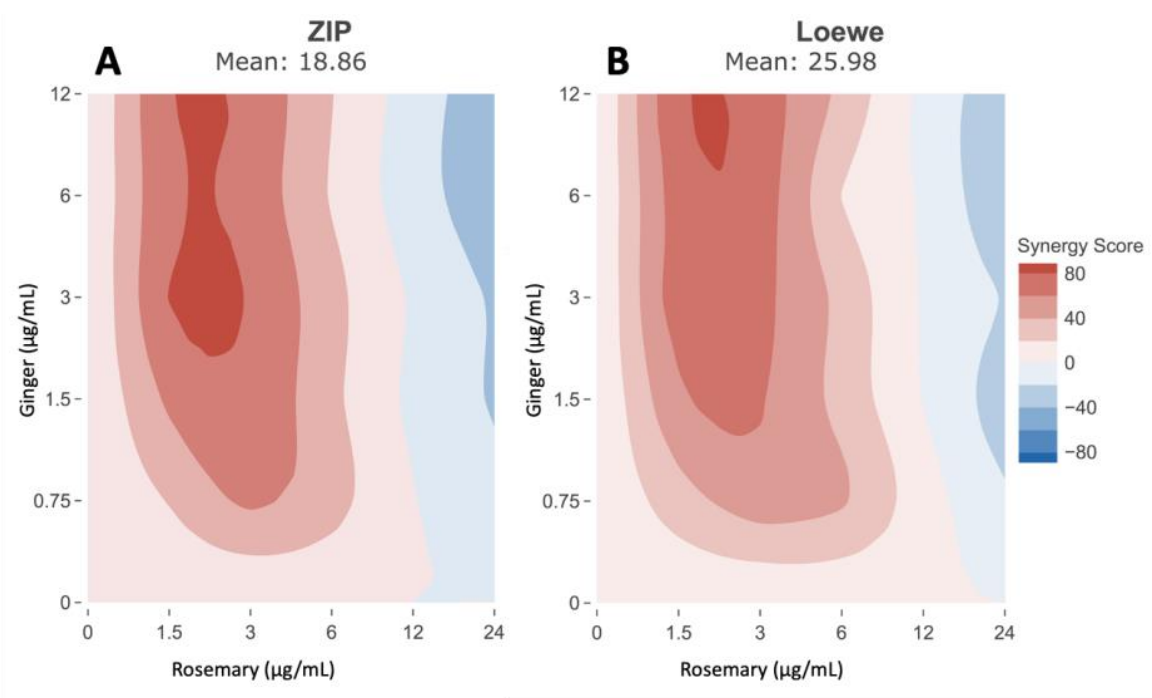

Figure 3 Combinatorial synergy analysis of HepG2 cells treated with Rosemary and Ginger extracts. Nrf2 activation by checkerboard combinations of Rosemary and Ginger extracts showed a strongly synergistic response as calculated using both $(A)$ the Zero Interaction Potency and (B) the Loewe additive effect reference synergy models (synergyfinder.org).

\subsection{Gene Expression and Effects}

\subsubsection{HepG2 Gene Expression by mRNA-seq Analysis}

In the present study the expression levels of 170 genes were increased and the expression levels of 247 genes were decreased by >2-fold in HepG2 cells treated for $16 \mathrm{~h}$ with $12 \mu \mathrm{g} / \mathrm{mL}$ PB123, determined by mRNA-seq on cell treatment groups with 4 biological replicate samples per group (Figure 4).

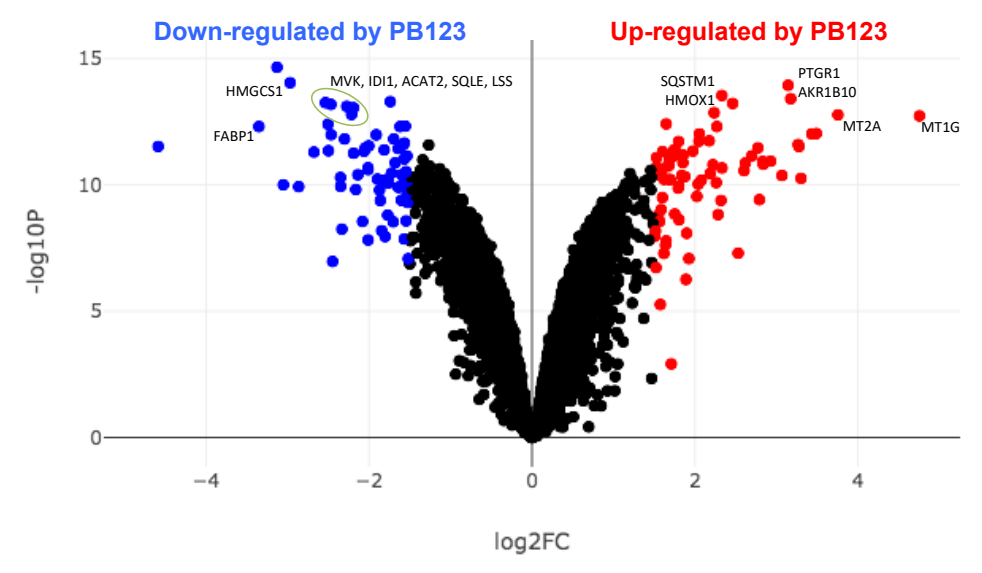

Figure 4 BioJupies was used to generate a Volcano plot of differentially expressed genes by HepG2 cells treated with PB123 $12 \mu \mathrm{g} / \mathrm{ml}$ compared with untreated control HepG2 cells. Red indicates upregulated genes and blue indicates downregulated genes. Genes were selected with 2-fold change threshold. Gene symbols on the plots are used to mark some of the most significant genes changed, showing lipid and cholesterol synthesis genes downregulated and Nrf2-dependent genes upregulated. 
To quantify gene expression changes caused by PB123, we utilized the mRNA-seq approach to measure gene expression levels using separately cultured HepG2 cells. Evaluation of the dataset using BioJupies showed that the primary transcription factor affected was Nrf2 (NFE2L2) (Figure 5).

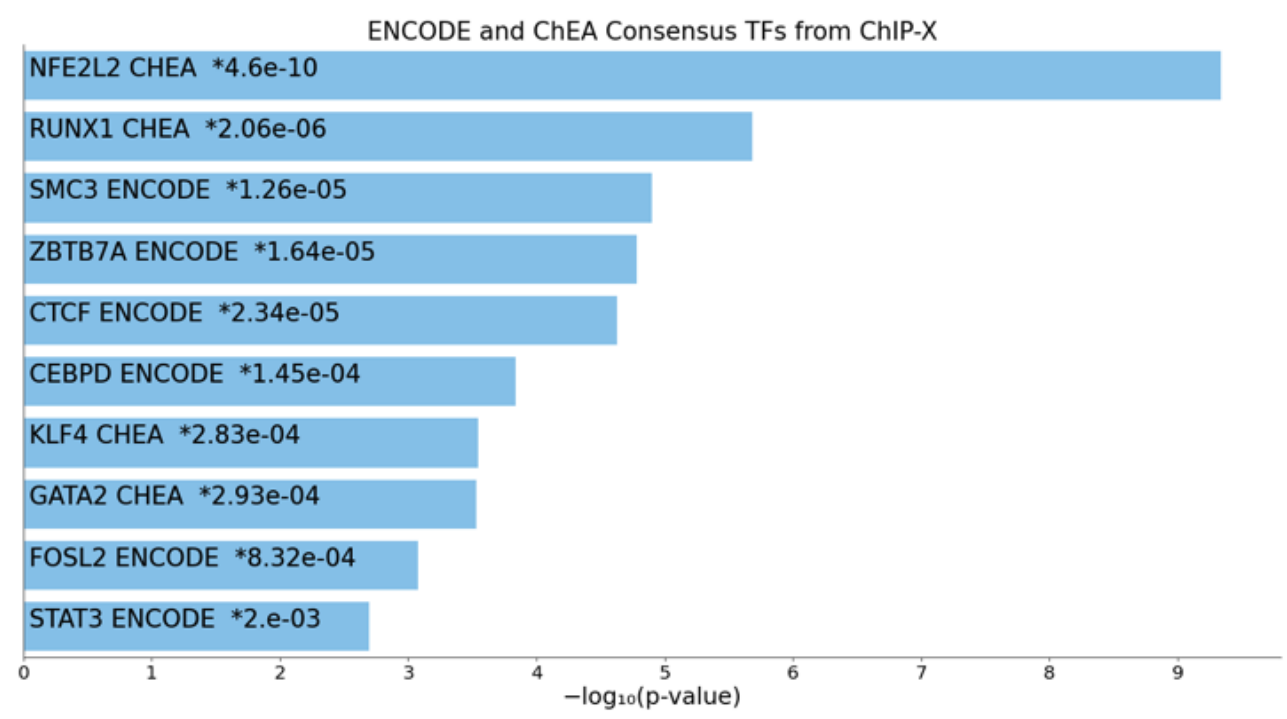

Figure 5 BioJupies was used to query ENCODE and ChEA consensus transcription factors with the DEG from the $12 \mu \mathrm{g} / \mathrm{mL}$ PB123 treatment mRNA-seq dataset and revealed prominent dependence on the Nrf2 (NFE2L2) transcription factor.

Ingenuity Pathway Analysis (IPA) likewise clearly demonstrated the primary importance of the Nrf2 transcription factor pathway in the differential gene expression induced by treatment of HepG2 cells with PB123 (Figure 6).

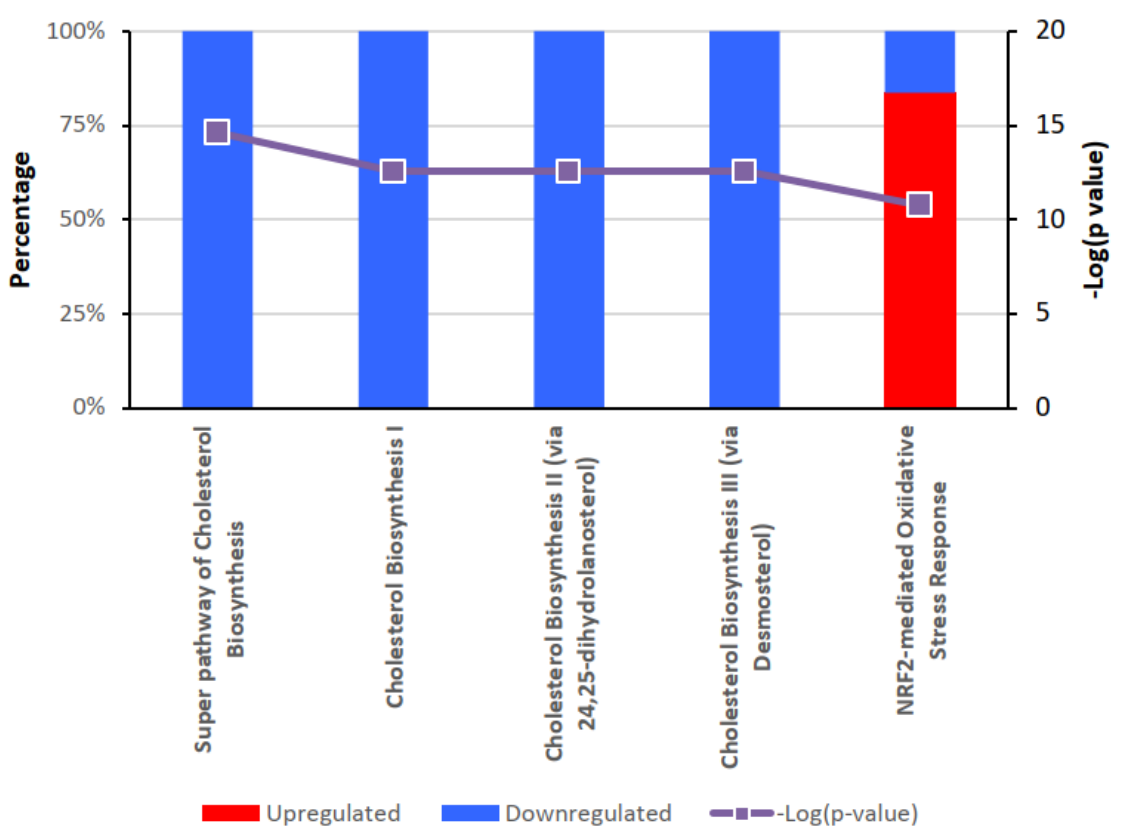

Figure 6 Ingenuity Pathway Analysis (IPA) indicates that PB123 downregulates genes in the cholesterol biosynthesis pathway and upregulates genes in the Nrf2 transcription factor pathway. 


\subsubsection{Pathways Involved}

PB123 induced Nrf2 activation and upregulation Nrf2-dependent genes, and BioJupies and Ingenuity Pathway Analysis (IPA) identified the key involvement of the Nrf2 pathway for gene expression changes induced by PB123. Analysis of differentially expressed genes by IPA revealed that that PB123 upregulates genes in the Nrf2 transcription factor pathway and downregulates genes in the cholesterol biosynthesis pathway (Figure 6). Likewise, data analysis using BioJupies of upregulated and downregulated differentially expressed genes in the PB123-treated HepG2 cells indicated that the top affected pathways by Wikipathways analysis included NRF2 pathway (up) and Cholesterol biosynthesis pathway (down). The upregulated and downregulated Wikipathways results are shown in Figure 7.

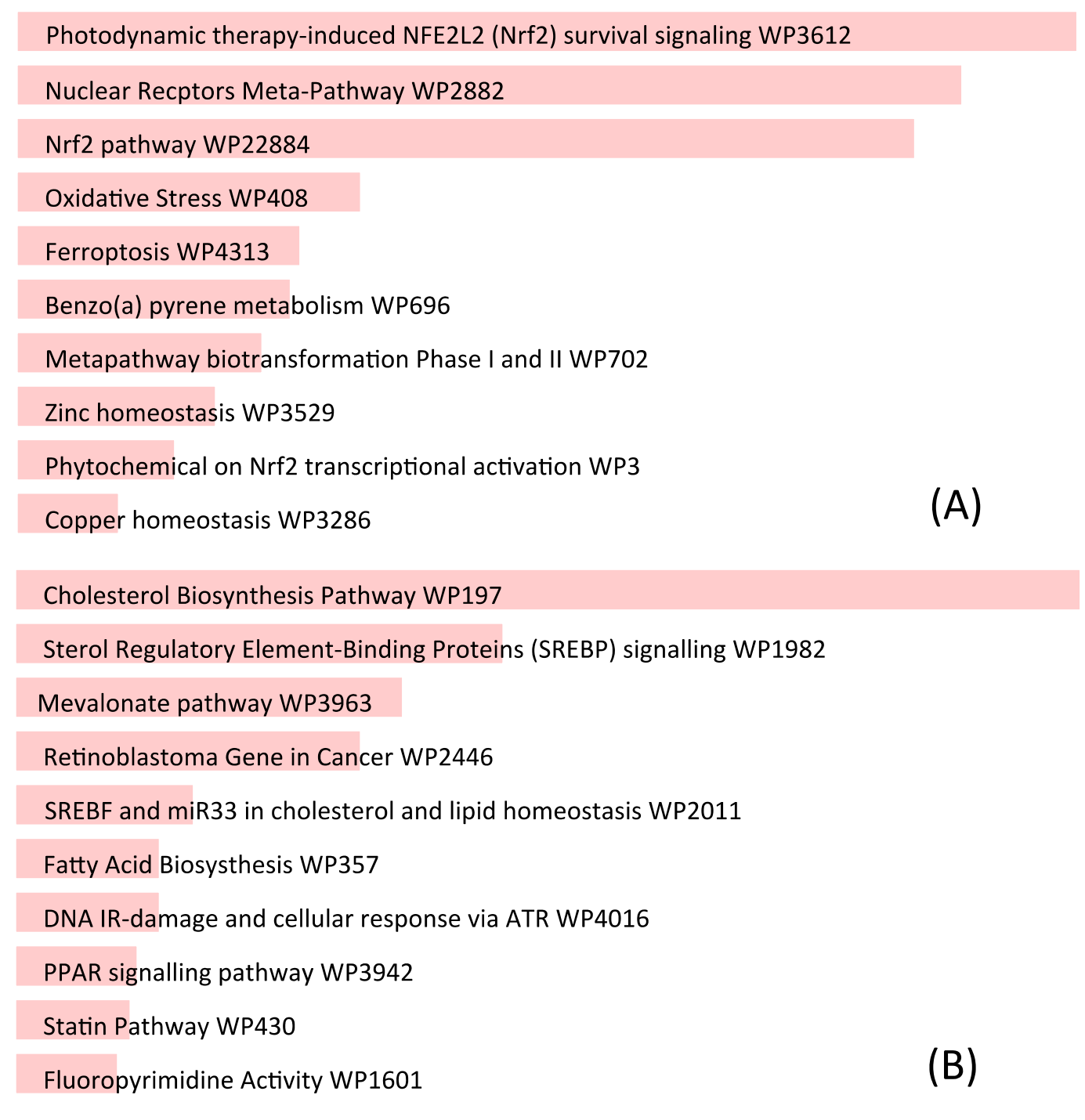

Figure 7 BioJupies was used to query Wikipathways to reveal the top pathways affected using the genes upregulated by PB123 (A) and downregulated by PB123 (B).

\subsubsection{Cellular Lipids}

PB123 induced downregulation of the Cholesterol Biosynthesis Pathway, so we evaluated the individual genes involved in the Wikipathway gene set for WP197 by their mRNA-seq gene 
expression values with 4 biological replicates per group (the WP197 pathway and the mRNA expression data are shown together in Figure 8). Because the PB123-induced downregulation of the genes in the Cholesterol Biosynthesis Pathway was so extensive and consistent, we followed up with examination of PB123-induced changes in the cellular total cholesterol levels. Treatment (24h) of HepG2 cells with PB123 at $5 \mu \mathrm{g} / \mathrm{mL}$ and at $12 \mu \mathrm{g} / \mathrm{mL}$ significantly decreased intracellular total cholesterol levels in the cells (Figure 9). In related work, Li, et al., reported that total cholesterol in HepG2 cells was decreased by treatment with 6-gingerol which is one of the most active phytochemicals from ginger [77].

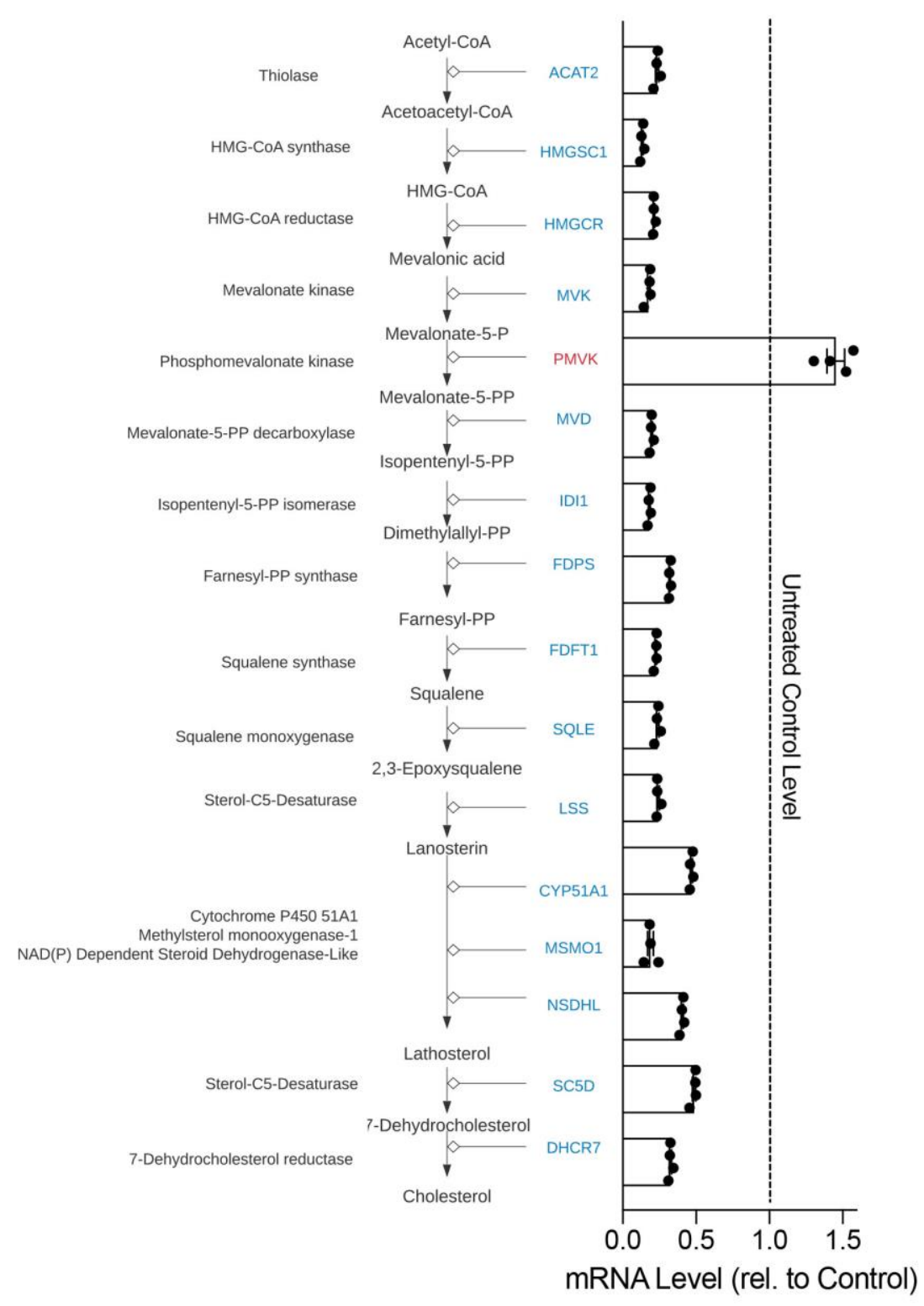

Figure 8 Cholesterol Biosynthesis Pathway genes from WikiPathways (WP197, https://www.wikipathways.org/index.php/Pathway:WP197). In our mRNA-seq dataset we found that all of the genes were significantly downregulated (shown in blue) by 12 $\mu \mathrm{g} / \mathrm{mL}$ PB123 in HepG2 cells except PMVK (shown in red) compared to control-treated HepG2 cells ( $p<0.05, \mathrm{n}=4$ per group). HMG-CoA reductase (HMGCR) is the rate-limiting enzyme in the pathway. 


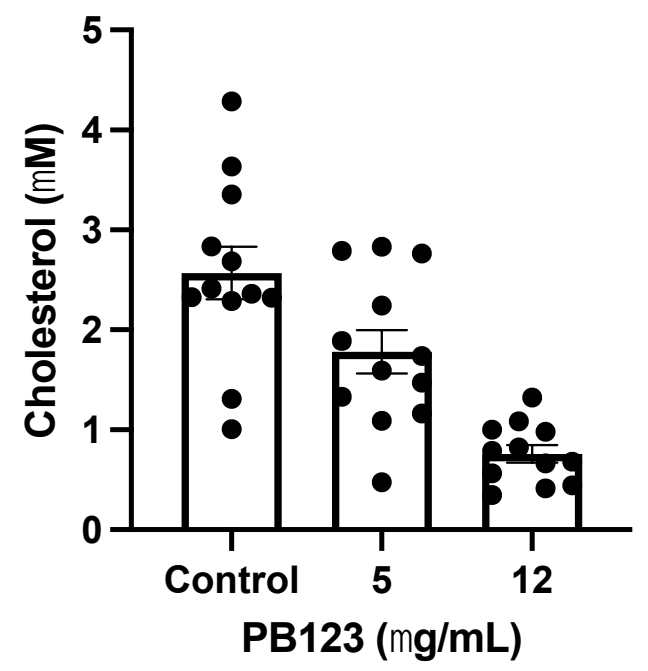

Figure 9 HepG2 total cholesterol. Total cholesterol levels were significantly reduced in HepG2 cells by 24 treatment with 5 or $12 \mu \mathrm{g} / \mathrm{mL}$ PB123 compared to untreated control HepG2 cells ( $p<0.05, n=12$ per group).

Examination of the highly downregulated PPAR signaling pathway WP3942 (Figure 7B) along with highly downregulated genes in the volcano plot (Figure 4) indicated a possible role for PB123induced downregulation of the fatty acid binding protein 1 gene FABP1. To follow up we evaluated the intracellular lipid droplet levels in HepG2 cells after $24 \mathrm{~h}$ of treatment with PB123 (0, 5, and 12 $\mu \mathrm{g} / \mathrm{mL}$ ). The FABP1 gene was significantly downregulated by both 5 and $12 \mu \mathrm{g} / \mathrm{mL}$ PB123 in HepG2 cells compared to control HepG2 cells (Figure 10A), and the HepG2 intracellular lipid content was significantly reduced by both 5 and $12 \mu \mathrm{g} / \mathrm{mL}$ PB123 (Figure 10B).
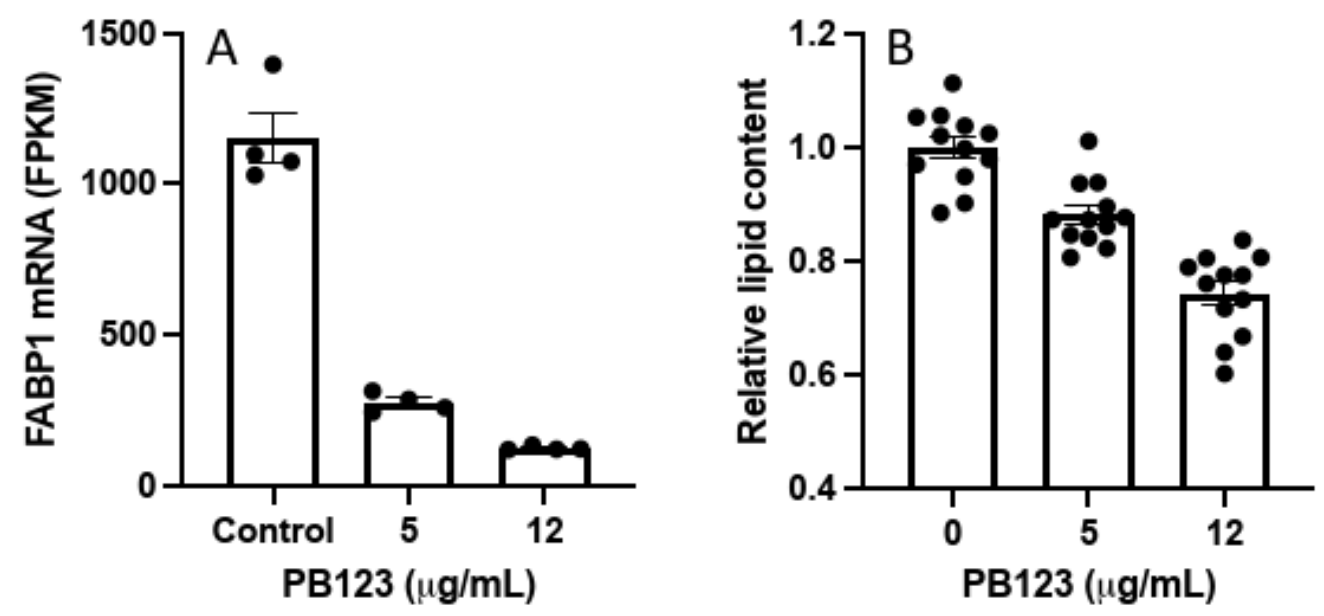

Figure 10 HepG2 intracellular lipids. We found that (A) FABP1 was significantly downregulated by both 5 and $12 \mu \mathrm{g} / \mathrm{mL}$ PB123 in HepG2 cells compared to untreated control HepG 2 cells ( $p<0.05, n=4$ per group), and (B) that intracellular lipid content was likewise significantly reduced by both 5 and $12 \mu \mathrm{g} / \mathrm{mL}$ PB123 in HepG2 cells compared to untreated control HepG2 cells ( $p<0.05, n=12$ per group). 


\subsubsection{HMOX1 mRNA and Protein}

PB123 treatment of HepG2 cells (24h) increased the expression of the HMOX1 gene (Figure 11A). As anticipated from the PB123-induced increase of HMOX1 gene expression, levels of intracellular HMOX1 protein were also elevated by treatment of HepG2 cells for $16 \mathrm{~h}$ with $5 \mu \mathrm{g} / \mathrm{mL}$ PB123 (Figure 11B).
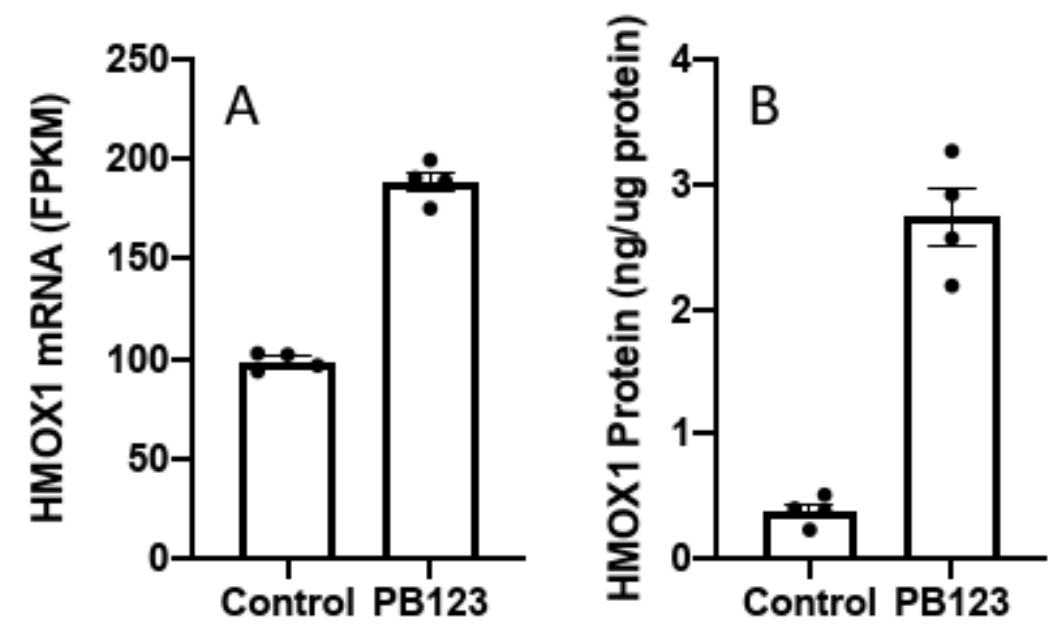

Figure 11 Heme oxygenase-1 gene expression and protein were increased in HepG2 cells by PB123 treatment. Treatment of HepG2 cells with PB123 $(5 \mu \mathrm{g} / \mathrm{mL}, 24 \mathrm{~h})$ increased the both the levels of HMOX1 gene expression determined by mRNA-seq $(A)$ and the levels of HMOX1 protein determined by ELISA (B), as expected based on the large PB123induced increase in Nrf2 activation ( $p<0.05, n=4$ in each case).

\subsubsection{Oxidative Stress Protection}

To assess cellular antioxidant defenses, we utilized the oxidant cumene hydroperoxide (CHP) to challenge HepG2 cells with an oxidative stress, with or without Nrf2 activation pretreatment with PB123. In a separate experiment, ERK1/2 kinase inhibition with PD98059, a selective and cell permeable inhibitor of the MEK/ERK pathway (10 $\mu \mathrm{M}$ PD98059, $30 \mathrm{~min}$ prior to treatment with PB123 or its individual components) was shown to decrease relative Nrf2 activation by PB123 and by each of the rosemary, ginger, and luteolin components (Table 1).

Table 1 Decrease of Nrf2 activation with ERK1/2 inhibition.

\begin{tabular}{lll}
\hline & Nrf2 Activator Alone & With ERK1/2 Inhibitor \\
\hline Rosemary & $100 \%$ & $51 \pm 4 \%$ \\
Ginger & $100 \%$ & $58 \pm 8 \%$ \\
Luteolin & $100 \%$ & $42 \pm 12 \%$ \\
PB123 & $100 \%$ & $58 \pm 4 \%$ \\
\hline
\end{tabular}


Based on that apparent ERK1/2 dependence of the Nrf2 response, the HepG2 cells were next cultured with $5 \mu \mathrm{g} / \mathrm{mL}$ PB123 for 16h, with or without $10 \mu \mathrm{M}$ PD98059, added 30 min prior to the PB123, then the media was removed and the cells were washed with PBS prior to adding fresh culture media to prevent possible direct scavenging of applied oxidants by PB123 components. Next the cells were challenged with cumene hydroperoxide for $6 \mathrm{~h}$ and cell injury assayed by measuring cell viability. Pretreatment with $5 \mu \mathrm{g} / \mathrm{mL}$ PB123 protected against oxidative-stress-induced loss of viability in HepG2 cells that were subsequently challenged with $25 \mu \mathrm{M}$ cumene hydroperoxide (Figure 12), but this protection was blocked if the ERK1/2 kinase was inhibited in the cells with PD98059.

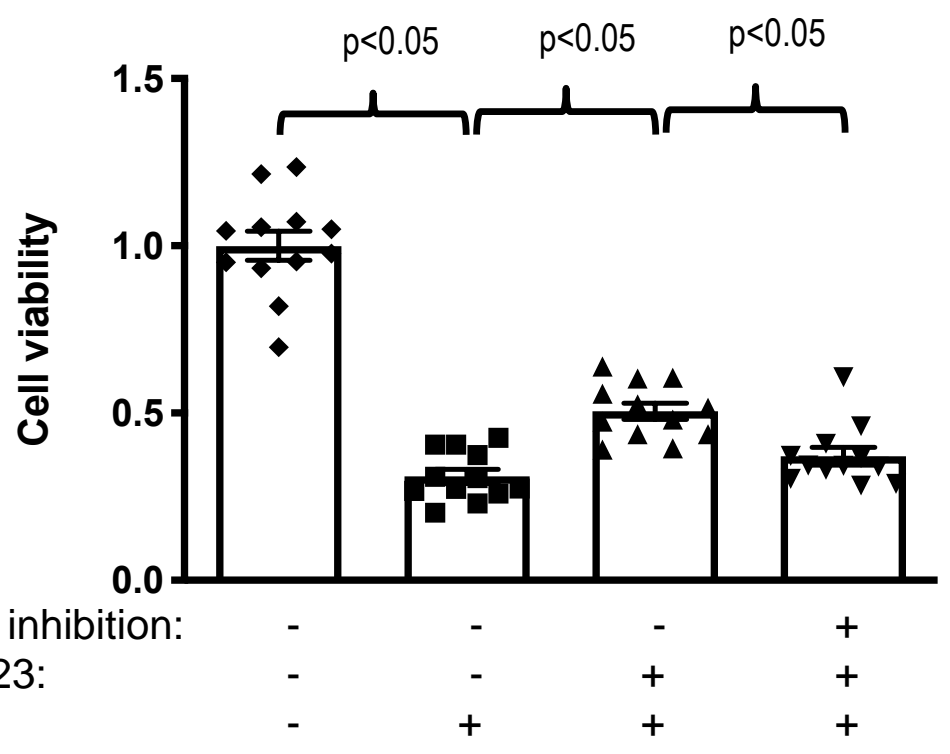

Figure 12 PB123 prevented loss of cell viability following challenge with an oxidative stress. Cytotoxicity was not observed (cell proliferation measured by CCK8 assay) in HepG2 cells treated for $16 \mathrm{~h}$ with $5 \mu \mathrm{g} / \mathrm{mL}$ PB123 compared to untreated control cells. In HepG2 cells treated with $5 \mu \mathrm{g} / \mathrm{mL}$ PB123 or vehicle control for $18 \mathrm{~h}$, and then challenged with $25 \mu \mathrm{M}$ cumene hydroperoxide $(\mathrm{CH})$ or untreated control for $6 \mathrm{~h}$, loss of cell viability (toxicity) was caused by $\mathrm{CH}$ challenge but this toxicity was partially attenuated $(p<0.05)$ by PB123 pretreatment. The protective effect of PB123 was blocked $(p<0.05)$ by ERK1/2 kinase inhibition (10 $\mu \mathrm{M}$ PD98059, $30 \mathrm{~min}$ prior to PB123 treatment).

\section{Discussion}

Aging has been associated with decreased ability to respond to stress-induced changes in gene expression in both animals [78] and humans [27]. Another key risk factor that increases with aging is dyslipidemia, which plays a key role in age-related cardiovascular disease [79]. Due to its welldocumented role in the regulation of antioxidant and anti-inflammatory defense mechanisms, Nrf2 activation may play a key role in protection against age-related physiological decline. In the present work we show that the PB123 phytochemical dietary supplement combination based on rosemary extract, ginger extract, and luteolin synergistically activates the Nrf2 pathway (Figure 1), with especially strong synergy between the rosemary and ginger extracts (Figure 3 ). 
The logic behind creating Nrf2 activators consisting of a combination of ingredients is threefold. First, the complexity of the Nrf2 activation/deactivation pathway is unusually great with dozens of control points having been demonstrated, ranging from promoter methylation and histone acetylation that regulate transcription of both KEAP1 and NFE2L2 (encoding Nrf2) genes, to numerous miRNAs that regulate translation of the transcripts [80-83], and luteolin participates at this epigenetic level of control. Once translated, regulation of the two proteins involves the more familiar array of covalent modifications involving electrophilic attack on the sulfhydryl groups of Keap1 which permit its release of Nrf2 [84]. Carnosic acid and carnosol from rosemary excel at this level of control as they behave as pro-drugs that possess little electrophilicity themselves but are converted to an electrophilic compound by the oxidative conditions at the site of the pathology that they are intended to alleviate $[35,85]$. By contrast, dimethyl fumarate, an FDA approved Nrf2 activator used to treat relapsing multiple sclerosis [86], displays strong electrophilic toxicity and alkylating ability [35], much like the classical Nrf2 activator sulforaphane [87]. Their toxicity manifests due to non-specific reactivity with cellular protein thiols and glutathione depletion. Nrf2 regulation also results from a variety of covalent modifications to the Nrf2 protein which include phosphorylation by kinases such as PKC [88], PI3K [89], and MAPK [90], plus sumoylation [91] and ubiquitinylation [92], all of which modify Nrf2's stability and ability to translocate to the nucleus. Once in the nucleus numerous other events regulate the ability of Nrf2 to regulate ARE/EpRE driven genes. These include acetylation/deacetylation of Nrf2 by Creb binding-protein and Sirt1 [93]. Acetylated Nrf2 was found to have augmented binding to the ARE promoter establishing acetylation as another regulatory mechanism for Nrf2 [94]. BACH1 is a negative regulator of Nrf2 and silencing it with siRNA increased expression of Nrf2 regulated genes [95]. Furthermore, this work suggested an interesting age-dependent difference in the expression profile of Nrf2-regulated genes due to increased Bach1 protein in older individuals. What appears to be another major controller of Nrf2 activity is the mechanism that ejects it from the nucleus, terminating its activity and tagging it for proteasomal degradation. The process is driven by activation and nuclear translocation of cytosolic Fyn kinase upon phosphorylation by GSK3 $\beta$. The active Fyn in the nucleus tags Nrf2 for ejection, ubiquitination, and protesomal destruction. Interestingly, the process is facilitated by and central to acetaminophen toxicity [96]. Luteolin and carnosic acid were found to inhibit the ejection of Nrf2 as follows: luteolin and carnosic acid both activate PI3K $[89,97]$ which not only phosphorylates Nrf2 to facilitate its translocation to the nucleus but which also activates Akt; Akt phosphorylates GSK3 $\beta$, inactivating it, which prevents it from activating cytosolic Fyn; the inactive Fyn remains in the cytosol and cannot enter the nucleus to contribute to the expulsion of Nrf2, meaning that active Nrf2 will have a longer duration in the nucleus, increasing its efficiency.

The second advantage of using multiple compounds to activate Nrf2 is that synergy that may result. Clearly, the activation of Nrf2 is not a linear pathway with a single rate-controlling step. Many of the contributing control points mentioned above may require the cooperation of other control points to realize maximal effect. For example, release of Nrf2 from Keap1 is necessary but not sufficient for a maximal effect-Nrf2's journey requires covalent modification by several possible mechanisms as mentioned above for nuclear entry. We have demonstrated substantial amounts of synergy by combining ingredients with diverse contributions to the process of Nrf2 activation [42, 67] as in the present study.

The third logical rationale for using a combination of ingredients to activate Nrf2 lies in the appreciation that activation is the result of not only a large number of control points, some positive 
and some negative, but that with a Nrf2 activation network that's this complicated (as opposed to a simple, linear pathway of activation), one may certainly need to combine agents that act at multiple key points in the network, with combined minimal toxicity, to expect a useful end result. As an example, single compounds that act only to release Nrf2 from Keap1 may indeed result in a rapid influx of Nrf2 to the nucleus, but it will be followed by an increased expulsion of that Nrf2 from the nucleus unless the Fyn-dependent export is simultaneously inhibited. Without slowing the exit pathway, Nrf2 stores in the cytosol would quickly become depleted, especially in elderly individuals as the rate of Nrf2 synthesis slows with aging $[78,98]$. The outdated paradigm of "One disease, one drug" that has driven recent decades of pharmacological thinking does not apply to network pharmacology [99].

In the present work, examining the upregulation of a well-established Nrf2-dependent gene to support PB123-induced Nrf2 activation, we found that the levels of the Nrf2-dependent HMOX1 gene (Figure 11A) and HMOX1 protein (Figure 11B) were increased in HepG2 cells by PB123 treatment. In addition, PB123 and its individual components showed ERK1/2 dependence for Nrf2 activation (Table 1 ) as well as for PB123-induced protection against cumene hydroperoxide-induced oxidative stress and loss of cell viability in HepG2 cells (Figure 12).

The PB123-induced downregulation of genes in the Cholesterol Biosynthesis Pathway (see Figure 8 ) is notable. PB123 treatment decreased the expression of fifteen genes involved in cholesterol biosynthesis (ACAT2, HMGSC1, HMGCR, MVK, MVD, IDI1, FDPS, FDFT1, SQLE, LSS, CYP51A1, MSMO1, $N S D H L, S C 5 D$, and $D H C R 7)$ and increased the expression of one gene in the pathway (PMVK). This result suggest that biosynthesis of cholesterol in HepG2 cells might be decreased by treatment with PB123, which was supported in a follow-up experiment demonstrating decreased levels of total cholesterol in HepG2 cells cultured with PB123 (Figure 9). Dietary approaches may be useful to help with healthy aging, with the goal of attenuating age-related dyslipidemia in combination with attenuating age-related oxidative stress and inflammation.

FABP1, also known as liver fatty acid binding protein, has high affinity for fatty acids by means of two fatty acid-binding sites [100]. FABP1 plays an important role in fatty acid uptake in HepG2 cells [101], leading to hypothesis that FABP1 may contribute to liver steatosis. Notably, silencing FABP1 decreased hepatic steatosis, inflammation, and oxidative stress in a mouse model of nonalcoholic fatty liver disease (NAFLD) [102]. Further, exercise was found to decrease FABP1 gene expression in mice and protect against NAFLD [103], and in human subjects urinary FABP1 protein levels were lowest in the fittest subjects, those with higher levels of muscle strength and aerobic fitness [104]. Recently, increased FABP1 levels in human subjects has been identified as a biomarker in diabetic nephropathy [105]. In our HepG2 cell experiments, the pronounced downregulation of FABP1 by PB123 (Figure 10A) was accompanied by a significant decrease in intracellular fatty acid levels in the cells (Figure 10B), similar to the results previously reported in HepG2 cells with FABP1 knocked down using antisense RNA [101].

Extensive prior work supports beneficial effects of the individual components of PB123 (rosemary, ginger, and luteolin) for normalizing lipid and cholesterol levels [106-114]. In our current work those benefits are likewise noted, along with the activation of the Nrf2 transcription factor, beneficial effects on gene regulation, and protection against oxidative stress. 


\section{Conclusions}

We found that the PB123 phytochemical combination is a potent Nrf2 activator with significant synergy between the rosemary and ginger components. Pathway analyses of genes differentially expressed by PB123 treatment of HepG2 cells in mRNA-seq experiments revealed prominent upregulation of genes in the Nrf2 pathway and downregulation of genes in the cholesterol biosynthesis pathway. Further, pretreatment with PB123 protected cultured HepG2 cells against an oxidative stress challenge caused by exposure to the organic oxidant cumene hydroperoxide. In addition, the downregulation of lipid uptake and cholesterol biosynthesis genes were accompanied by decreased intracellular lipid levels and decreased total cholesterol levels in PB123-treated HepG2 cells. The Nrf2 activation, highly synergistic effects between the rosemary and ginger ingredients, differential gene expression in pathways that pertain to increased cytoprotection, decreased cholesterol synthesis, and decreased intracellular lipid accumulation by the dietary supplement PB123 support its use to promote healthy aging.

\section{Acknowledgments}

The authors thank Steve Simmons for kindly providing a sample of the stably transduced HepG2ARE cell line, and Avi Ma'ayan and his research team for assistance with loading our FASTQ data in BioJupies. This work utilized the Genomics Shared Resource of the University of Colorado Cancer Center (P30CA046934).

\section{Author Contributions}

Conceptualization (B.M.H., B.G., J.M.M.); methodology (B.M.H., B.G.); investigation (B.M.H., B.G.); data analysis (B.M.H., B.G., J.M.M.); manuscript preparation (B.M.H.), manuscript review and editing (B.M.H., B.G., J.M.M.)

\section{Funding}

This research was funded in part by grant number 1R43AG053128 from the National Institutes of Health $(\mathrm{NIH})$ of the United States.

\section{Competing Interests}

B.M.H., B.G., and J.M.M. are cofounders of Pathways Bioscience which developed the PB123 dietary supplement. The NIH funders had no role in the design of the study, in the collection, analyses, or interpretation of data, in the writing of the manuscript, or in the decision to publish the results.

\section{References}

1. Harman D. Aging: A theory based on free radical and radiation chemistry. J Gerontol. 1956; 11: 298-300.

2. Harman D. The aging process. Proc Natl Acad Sci USA. 1981; 78: 7124-7128.

3. Harman D. Nutritional implications of the free-radical theory of aging. J Am Coll Nutr. 1982; 1 : 27-34. 
4. Beckman KB, Ames BN. The free radical theory of aging matures. Physiol Rev. 1998; 78: 547-581.

5. Pomatto LC, Davies KJ. Adaptive homeostasis and the free radical theory of ageing. Free Radic Biol Med. 2018; 124: 420-430.

6. Kiefte-de Jong JC, Mathers JC, Franco $\mathrm{OH}$. Nutrition and healthy ageing: The key ingredients. Proc Nutr Soc. 2014; 73: 249-259.

7. Cannella C, Savina C, Donini LM. Nutrition, longevity and behavior. Arch Gerontol Geriatr. 2009; 49: 19-27.

8. Harman D. Free radical theory of aging: Dietary implications. Am J Clin Nutr. 1972; 25: 839-843.

9. Prior RL, Cao G, Prior RL, Cao G. Analysis of botanicals and dietary supplements for antioxidant capacity: A review. J AOAC Int. 2000; 83: 950-956.

10. Ninfali P, Mea G, Giorgini S, Rocchi M, Bacchiocca M. Antioxidant capacity of vegetables, spices and dressings relevant to nutrition. Br J Nutr. 2005; 93: 257-266.

11. Nelson SK, Bose SK, Grunwald GK, Myhill P, McCord JM. The induction of human superoxide dismutase and catalase in vivo: A fundamentally new approach to antioxidant therapy. Free Radic Biol Med. 2006; 40: 341-347.

12. Lewis KN, Mele J, Hayes JD, Buffenstein R. Nrf2, a guardian of healthspan and gatekeeper of species longevity. Integr Comp Biol. 2010; 50: 829-843.

13. Cardozo LF, Pedruzzi LM, Stenvinkel P, Stockler-Pinto MB, Daleprane JB, Leite Jr $M$, et al. Nutritional strategies to modulate inflammation and oxidative stress pathways via activation of the master antioxidant switch Nrf2. Biochimie. 2013; 95: 1525-1533.

14. Kelsey NA, Wilkins HM, Linseman DA. Nutraceutical antioxidants as novel neuroprotective agents. Molecules. 2010; 15: 7792-7814.

15. Lee JM, Li J, Johnson DA, Stein TD, Kraft AD, Calkins MJ, et al. Nrf2, a multi-organ protector? FASEB J. 2005; 19: 1061-1066.

16. Eggler AL, Gay KA, Mesecar AD. Molecular mechanisms of natural products in chemoprevention: Induction of cytoprotective enzymes by Nrf2. Mol Nutr Food Res. 2008; 52: S84-S94.

17. Na HK, Surh YJ. Modulation of Nrf2-mediated antioxidant and detoxifying enzyme induction by the green tea polyphenol EGCG. Food Chem Toxicol. 2008; 46: 1271-1278.

18. Li J, Ichikawa T, Janicki JS, Cui T. Targeting the Nrf2 pathway against cardiovascular disease. Expert Opin Ther Targets. 2009; 13: 785-794.

19. Cho HY, Kleeberger SR. Nrf2 protects against airway disorders. Toxicol Appl Pharmacol. 2010; 244: 43-56.

20. Wakabayashi N, Slocum SL, Skoko JJ, Shin S, Kensler TW. When NRF2 talks, who's listening? Antioxid Redox Signal. 2010; 13: 1649-1663.

21. Klaassen CD, Reisman SA. Nrf2 the rescue: Effects of the antioxidative/electrophilic response on the liver. Toxicol Appl Pharmacol. 2010; 244: 57-65.

22. Kwak MK, Kensler TW. Targeting NRF2 signaling for cancer chemoprevention. Toxicol Appl Pharmacol. 2010; 244: 66-76.

23. Sykiotis GP, Bohmann D. Stress-activated cap'n'collar transcription factors in aging and human disease. Sci Signal. 2010; 3: re3.

24. Suh JH, Shenvi SV, Dixon BM, Liu H, Jaiswal AK, Liu RM, et al. Decline in transcriptional activity of Nrf2 causes age-related loss of glutathione synthesis, which is reversible with lipoic acid. Proc Natl Acad Sci USA. 2004; 101: 3381-3386.

25. Smith EJ, Shay KP, Thomas NO, Butler JA, Finlay LF, Hagen TM. Age-related loss of hepatic Nrf2 
protein homeostasis: Potential role for heightened expression of miR-146a. Free Radic Biol Med. 2015; 89: 1184-1191.

26. Shay KP, Michels AJ, Li W, Kong A-NT, Hagen TM. Cap-independent Nrf2 translation is part of a lipoic acid-stimulated detoxification stress response. Biochim Biophys Acta Mol Cell Res. 2012; 1823: 1102-1109.

27. Zhou L, Zhang H, Davies KJ, Forman HJ. Aging-related decline in the induction of Nrf2-regulated antioxidant genes in human bronchial epithelial cells. Redox Biol. 2018; 14: 35-40.

28. Kubo E, Chhunchha B, Singh P, Sasaki H, Singh DP. Sulforaphane reactivates cellular antioxidant defense by inducing Nrf2/ARE/Prdx6 activity during aging and oxidative stress. Sci Rep. 2017; 7: 14130.

29. Lewis KN, Wason E, Edrey YH, Kristan DM, Nevo E, Buffenstein R. Regulation of Nrf2 signaling and longevity in naturally long-lived rodents. Proc Natl Acad Sci USA. 2015; 112: 3722-3727.

30. Jung S, Kim M, Ryu HJ, Chae JS, Lee S-H, Lee JH. Age-related increase in LDL-cholesterol is associated with enhanced oxidative stress and disturbed sphingolipid metabolism. Metabolomics. 2015; 11: 40-49.

31. Parini P, Angelin B, Rudling M. Cholesterol and lipoprotein metabolism in aging: Reversal of hypercholesterolemia by growth hormone treatment in old rats. Arterioscler Thromb Vasc Biol. 1999; 19: 832-839.

32. Pourmasoumi M, Hadi A, Rafie N, Najafgholizadeh A, Mohammadi H, Rouhani MH. The effect of ginger supplementation on lipid profile: A systematic review and meta-analysis of clinical trials. Phytomedicine. 2018; 43: 28-36.

33. Petiwala SM, Johnson JJ. Diterpenes from rosemary (Rosmarinus officinalis): Defining their potential for anti-cancer activity. Cancer Lett. 2015; 367: 93-102.

34. Xiang Q, Liu Z, Wang Y, Xiao H, Wu W, Xiao C, et al. Carnosic acid attenuates lipopolysaccharideinduced liver injury in rats via fortifying cellular antioxidant defense system. Food Chem Toxicol. 2013; 53: 1-9.

35. Satoh T, McKercher SR, Lipton SA. Nrf2/ARE-mediated antioxidant actions of pro-electrophilic drugs. Free Radic Biol Med. 2013; 65: 645-657.

36. Satoh T, Kosaka K, Itoh K, Kobayashi A, Yamamoto M, Shimojo Y, et al. Carnosic acid, a catecholtype electrophilic compound, protects neurons both in vitro and in vivo through activation of the Keap1/Nrf2 pathway via S-alkylation of targeted cysteines on Keap1. J Neurochem. 2008; 104: 1116-1131.

37. Foresti R, Bains SK, Pitchumony TS, de Castro Bras LE, Drago F, Dubois-Rande JL, et al. Small molecule activators of the Nrf2-HO-1 antioxidant axis modulate heme metabolism and inflammation in BV2 microglia cells. Pharmacol Res. 2013; 76: 132-148.

38. Johnson JJ. Carnosol: A promising anti-cancer and anti-inflammatory agent. Cancer Lett. 2011; 305: 1-7.

39. Martin D, Rojo Al, Salinas M, Diaz R, Gallardo G, Alam J, et al. Regulation of heme oxygenase-1 expression through the phosphatidylinositol 3-kinase/Akt pathway and the Nrf2 transcription factor in response to the antioxidant phytochemical carnosol. J Biol Chem. 2004; 279: 89198929.

40. Wen Z, Wang Z, Wang S, Ravula R, Yang L, Xu J, et al. Discovery of molecular mechanisms of traditional Chinese medicinal formula Si-Wu-Tang using gene expression microarray and connectivity map. PLoS ONE. 2011; 6: e18278. 
41. Priyandoko D, Ishii T, Kaul SC, Wadhwa R. Ashwagandha leaf derived withanone protects normal human cells against the toxicity of methoxyacetic acid, a major industrial metabolite. PLoS ONE. 2011; 6: e19552.

42. Velmurugan K, Alam J, McCord JM, Pugazhenthi S. Synergistic induction of heme oxygenase-1 by the components of the antioxidant supplement Protandim. Free Radic Biol Med. 2009; 46: 430-440.

43. Mishra LC, Singh BB, Dagenais S. Scientific basis for the therapeutic use of Withania somnifera (ashwagandha): A review. Altern Med Rev. 2000; 5: 334-346.

44. Paredes-Gonzalez X, Fuentes F, Jeffery S, Saw CL, Shu L, Su ZY, et al. Induction of NRF2-mediated gene expression by dietary phytochemical flavones apigenin and luteolin. Biopharm Drug Dispos. 2015; 36: 440-451.

45. Xu J, Wang H, Ding K, Zhang L, Wang C, Li T, et al. Luteolin provides neuroprotection in models of traumatic brain injury via the Nrf2-ARE pathway. Free Radic Biol Med. 2014; 71: 186-195.

46. Zhang YC, Gan FF, Shelar SB, Ng KY, Chew EH. Antioxidant and Nrf2 inducing activities of luteolin, a flavonoid constituent in Ixeris sonchifolia Hance, provide neuroprotective effects against ischemia-induced cellular injury. Food Chem Toxicol. 2013; 59: 272-280.

47. Sun GB, Sun X, Wang M, Ye JX, Si JY, Xu HB, et al. Oxidative stress suppression by luteolin-induced heme oxygenase-1 expression. Toxicol Appl Pharmacol. 2012; 265: 229-240.

48. Lin CW, Wu MJ, Liu IY, Su JD, Yen JH. Neurotrophic and cytoprotective action of luteolin in PC12 cells through ERK-dependent induction of Nrf2-driven HO-1 expression. J Agric Food Chem. 2010; 58: 4477-4486.

49. Raskovic A, Milanovic I, Pavlovic N, Cebovic T, Vukmirovic S, Mikov M. Antioxidant activity of rosemary (Rosmarinus officinalis L.) essential oil and its hepatoprotective potential. BMC Complement Altern Med. 2014; 14: 225.

50. Ortuno J, Serrano R, Banon S. Antioxidant and antimicrobial effects of dietary supplementation with rosemary diterpenes (carnosic acid and carnosol) vs vitamin $\mathrm{E}$ on lamb meat packed under protective atmosphere. Meat Sci. 2015; 110: 62-69.

51. Klancnik A, Guzej B, Kolar MH, Abramovic H, Mozina SS. In vitro antimicrobial and antioxidant activity of commercial rosemary extract formulations. J Food Prot. 2009; 72: 1744-1752.

52. Emami F, Ali-Beig H, Farahbakhsh S, Mojabi N, Rastegar-Moghadam B, Arbabian S, et al. Hydroalcoholic extract of Rosemary (Rosmarinus officinalis L.) and its constituent carnosol inhibit formalin-induced pain and inflammation in mice. Pak J Biol Sci. 2013; 16: 309-316.

53. Del Campo J, Amiot MJ, Nguyen-The C. Antimicrobial effect of rosemary extracts. J Food Prot. 2000; 63: 1359-1368.

54. Bozin B, Mimica-Dukic N, Samojlik I, Jovin E. Antimicrobial and antioxidant properties of rosemary and sage (Rosmarinus officinalis L. and Salvia officinalis L., Lamiaceae) essential oils. J Agric Food Chem. 2007; 55: 7879-7885.

55. Bak MJ, OkS, Jun M, Jeong WS. 6-shogaol-rich extract from ginger up-regulates the antioxidant defense systems in cells and mice. Molecules. 2012; 17: 8037-8055.

56. Wang S, Zhang C, Yang G, Yang Y. Biological properties of 6-gingerol: A brief review. Nat Prod Commun. 2014; 9: 1027-1030.

57. Wilson PB. Ginger (Zingiber officinale) as an analgesic and ergogenic aid in sport: A systemic review. J Strength Cond Res. 2015; 29: 2980-2995.

58. Chen H, Fu J, Chen H, Hu Y, Soroka DN, Prigge JR, et al. Ginger compound [6]-shogaol and its 
cysteine-conjugated metabolite (M2) activate Nrf2 in colon epithelial cells in vitro and in vivo. Chem Res Toxicol. 2014; 27: 1575-1585.

59. Zick SM, Djuric Z, Ruffin MT, Litzinger AJ, Normolle DP, Alrawi S, et al. Pharmacokinetics of 6gingerol, 8-gingerol, 10-gingerol, and 6-shogaol and conjugate metabolites in healthy human subjects. Cancer Epidemiol Biomarkers Prev. 2008; 17: 1930-1936.

60. Seelinger G, Merfort I, Schempp CM. Anti-oxidant, anti-inflammatory and anti-allergic activities of luteolin. Planta Med. 2008; 74: 1667-1677.

61. Kim YJ, Park MY, Chang N, Kwon O. Intake and major sources of dietary flavonoid in Korean adults: Korean National Health and Nutrition Examination Survey 2010-2012. Asia Pac J Clin Nutr. 2015; 24: 456-463.

62. Jun $\mathrm{S}$, Shin $\mathrm{S}$, Joung $\mathrm{H}$. Estimation of dietary flavonoid intake and major food sources of Korean adults. Br J Nutr. 2016; 115: 480-489.

63. Chun OK, Chung SJ, Song WO. Estimated dietary flavonoid intake and major food sources of U.S. adults. J Nutr. 2007; 137: 1244-1252.

64. Nabavi SF, Braidy N, Gortzi O, Sobarzo-Sanchez E, Daglia M, Skalicka-Woźniak K, et al. Luteolin as an anti-inflammatory and neuroprotective agent: A brief review. Brain Res Bull. 2015; 119: 111.

65. Taliou A, Zintzaras E, Lykouras L, Francis K. An open-label pilot study of a formulation containing the anti-inflammatory flavonoid luteolin and its effects on behavior in children with autism spectrum disorders. Clin Ther. 2013; 35: 592-602.

66. Kukoyi AT, Fan X, Staitieh BS, Hybertson BM, Gao B, McCord JM, et al. MiR-144 mediates Nrf2 inhibition and alveolar epithelial dysfunction in HIV-1 transgenic rats. Am J Physiol Cell Physiol. 2019; 317: C390-C397.

67. Hybertson BM, Gao B, Bose S, McCord JM. Phytochemical combination PB125 activates the Nrf2 pathway and induces cellular protection against oxidative injury. Antioxidants. 2019; 8: 119.

68. Simmons SO, Fan CY, Yeoman K, Wakefield J, Ramabhadran R. NRF2 oxidative stress induced by heavy metals is cell type dependent. Curr Chem Genom. 2011; 5: 1-12.

69. Krajka-Kuzniak V, Paluszczak J, Szaefer H, Baer-Dubowska W. The activation of the Nrf2/ARE pathway in HepG2 hepatoma cells by phytochemicals and subsequent modulation of phase II and antioxidant enzyme expression. J Physiol Biochem. 2015; 71: 227-238.

70. Javitt NB. Hep G2 cells as a resource for metabolic studies: Lipoprotein, cholesterol, and bile acids. FASEB J. 1990; 4: 161-168.

71. Wu TD, Nacu S. Fast and SNP-tolerant detection of complex variants and splicing in short reads. Bioinformatics. 2010; 26: 873-881.

72. Trapnell C, Williams BA, Pertea G, Mortazavi A, Kwan G, van Baren MJ, et al. Transcript assembly and quantification by RNA-Seq reveals unannotated transcripts and isoform switching during cell differentiation. Nat Biotechnol. 2010; 28: 511-515.

73. Baird NL, Bowlin JL, Cohrs RJ, Gilden D, Jones KL. Comparison of varicella-zoster virus RNA sequences in human neurons and fibroblasts. J Virol. 2014; 88: 5877-5880.

74. Xie Z, Bailey A, Kuleshov MV, Clarke DJ, Evangelista JE, Jenkins SL, et al. Gene set knowledge discovery with Enrichr. Curr Protoc. 2021; 1: e90.

75. Torre D, Lachmann A, Ma'ayan A. BioJupies: Automated generation of interactive notebooks for RNA-Seq data analysis in the cloud. Cell Syst. 2018; 7: 556-561.e3.

76. Lowry $\mathrm{OH}$, Rosebrough NJ, Farr AL, Randall RJ. Protein measurement with the Folin phenol 
reagent. J Biol Chem. 1951; 193: 265-275.

77. Li X, Guo J, Liang N, Jiang X, Song $Y$, Ou S, et al. 6-Gingerol regulates hepatic cholesterol metabolism by up-regulation of LDLR and cholesterol efflux-related genes in HepG2 Cells. Front Pharmacol. 2018; 9: 159.

78. Zhang H, Davies KJ, Forman HJ. Oxidative stress response and Nrf2 signaling in aging. Free Radic Biol Med. 2015; 88: 314-336.

79. Liu HH, Li JJ. Aging and dyslipidemia: A review of potential mechanisms. Ageing Res Rev. 2015; 19: 43-52.

80. Guo Y, Yu S, Zhang C, Kong AN. Epigenetic regulation of Keap1-Nrf2 signaling. Free Radic Biol Med. 2015; 88: 337-349.

81. Kang KA, Piao MJ, Hyun YJ, Zhen AX, Cho SJ, Ahn MJ, et al. Luteolin promotes apoptotic cell death via upregulation of Nrf2 expression by DNA demethylase and the interaction of Nrf2 with p53 in human colon cancer cells. Exp Mol Med. 2019; 51: 1-14.

82. Zuo Q, Wu R, Xiao X, Yang C, Yang Y, Wang C, et al. The dietary flavone luteolin epigenetically activates the Nrf2 pathway and blocks cell transformation in human colorectal cancer HCT116 cells. J Cell Biochem. 2018; 119: 9573-9582.

83. Wang L, Zhang C, Guo Y, Su ZY, Yang Y, Shu L, et al. Blocking of JB6 cell transformation by tanshinone IIA: Epigenetic reactivation of Nrf2 antioxidative stress pathway. AAPS J. 2014; 16: 1214-1225.

84. Dinkova-Kostova AT, Holtzclaw WD, Cole RN, Itoh K, Wakabayashi N, Katoh Y, et al. Direct evidence that sulfhydryl groups of Keap1 are the sensors regulating induction of phase 2 enzymes that protect against carcinogens and oxidants. Proc Natl Acad Sci USA. 2002; 99: 11908-11913.

85. Satoh T, Lipton S. Recent advances in understanding NRF2 as a druggable target: Development of pro-electrophilic and non-covalent NRF2 activators to overcome systemic side effects of electrophilic drugs like dimethyl fumarate. F1000Res. 2017; 6: 2138.

86. Prosperini L, Pontecorvo S. Dimethyl fumarate in the management of multiple sclerosis: Appropriate patient selection and special considerations. Ther Clin Risk Manag. 2016; 12: 339350.

87. Izumi Y, Kataoka H, Inose Y, Akaike A, Koyama Y, Kume T. Neuroprotective effect of an Nrf2-ARE activator identified from a chemical library on dopaminergic neurons. Eur J Pharmacol. 2018; 818: 470-479.

88. Huang HC, Nguyen T, Pickett CB. Phosphorylation of Nrf2 at Ser-40 by protein kinase $\mathrm{C}$ regulates antioxidant response element-mediated transcription. J Biol Chem. 2002; 277: 42769-42774.

89. de Oliveira MR, Ferreira GC, Schuck PF, Dal Bosco SM. Role for the PI3K/Akt/Nrf2 signaling pathway in the protective effects of carnosic acid against methylglyoxal-induced neurotoxicity in SH-SY5Y neuroblastoma cells. Chem Biol Interact. 2015; 242: 396-406.

90. Tian Y, Su Y, Ye Q, Chen L, Yuan F, Wang Z. Silencing of TXNIP alleviated oxidative stress injury by regulating MAPK-Nrf2 axis in ischemic stroke. Neurochem Res. 2020; 45: 428-436.

91. Walters TS, McIntosh DJ, Ingram SM, Tillery L, Motley ED, Arinze IJ, et al. SUMO-modification of Human Nrf2 at $K(110)$ and $K(533)$ regulates its nucleocytoplasmic localization, stability and transcriptional activity. Cell Physiol Biochem. 2021; 55: 141-159.

92. Mclntosh DJ, Walters TS, Arinze IJ. Arkadia (RING finger protein 111) mediates sumoylationdependent stabilization of Nrf2 through K48-linked ubiquitination. Cell Physiol Biochem. 2018; 
46: 418-430.

93. Kawai Y, Garduno L, Theodore M, Yang J, Arinze IJ. Acetylation-deacetylation of the transcription factor Nrf2 (nuclear factor erythroid 2-related factor 2) regulates its transcriptional activity and nucleocytoplasmic localization. J Biol Chem. 2011; 286: 7629-7640.

94. Sun Z, Chin YE, Zhang DD. Acetylation of Nrf2 by p300/CBP augments promoter-specific DNA binding of Nrf2 during the antioxidant response. Mol Cell Biol. 2009; 29: 2658-2672.

95. Zhang H, Zhou L, Davies KJ, Forman HJ. Silencing Bach1 alters aging-related changes in the expression of Nrf2-regulated genes in primary human bronchial epithelial cells. Arch Biochem Biophys. 2019; 672: 108074.

96. Mathur A, Rizvi F, Kakkar P. PHLPP2 down regulation influences nuclear Nrf2 stability via Akt1/Gsk3beta/Fyn kinase axis in acetaminophen induced oxidative renal toxicity: Protection accorded by morin. Food Chem Toxicol. 2016; 89: 19-31.

97. Yang JT, Wang J, Zhou XR, Xiao C, Lou YY, Tang LH, et al. Luteolin alleviates cardiac ischemia/reperfusion injury in the hypercholesterolemic rat via activating Akt/Nrf2 signaling. Naunyn Schmiedebergs Arch Pharmacol. 2018; 391: 719-728.

98. Pomatto LC, Davies KJ. The role of declining adaptive homeostasis in ageing. J Physiol. 2017; 595: 7275-7309.

99. Hopkins AL. Network pharmacology: The next paradigm in drug discovery. Nat Chem Biol. 2008; 4: 682-690.

100.Lehner R, Quiroga AD. Chapter 5-Fatty acid handling in mammalian cells. In: Biochemistry of lipids, lipoproteins and membranes. 6th ed. Boston: Elsevier; 2016. pp.149-184.

101.Wolfrum C, Buhlmann C, Rolf B, Börchers T, Spener F. Variation of liver-type fatty acid binding protein content in the human hepatoma cell line HepG2 by peroxisome proliferators and antisense RNA affects the rate of fatty acid uptake. Biochim Biophys Acta Mol Cell Biol Lipids. 1999; 1437: 194-201.

102.Mukai T, Egawa M, Takeuchi T, Yamashita H, Kusudo T. Silencing of FABP1 ameliorates hepatic steatosis, inflammation, and oxidative stress in mice with nonalcoholic fatty liver disease. FEBS Open Bio. 2017; 7: 1009-1016.

103.Pi H, Liu M, Xi Y, Chen M, Tian L, Xie J, et al. Long-term exercise prevents hepatic steatosis: A novel role of FABP1 in regulation of autophagy-lysosomal machinery. FASEB J. 2019; 33: 1187011883.

104.Kosaki K, Kamijo-lkemori A, Sugaya T, Tanahashi K, Kumagai H, Sawano Y, et al. Relationship between exercise capacity and urinary liver-type fatty acid-binding protein in middle-aged and older individuals. Clin Exp Nephrol. 2017; 21: 810-817.

105.Tsai IT, Wu CC, Hung WC, Lee TL, Hsuan CF, Wei CT, et al. FABP1 and FABP2 as markers of diabetic nephropathy. Int J Med Sci. 2020; 17: 2338-2345.

106.Wang SJ, Chen Q, Liu MY, Yu HY, Xu JQ, Wu JQ, et al. Regulation effects of rosemary (Rosmarinus officinalis Linn.) on hepatic lipid metabolism in OA induced NAFLD rats. Food Funct. 2019; 10: 7356-7365.

107.Luis Martínez-Rodríguez J, Gutiérrez-Hernández R, Araceli Reyes-Estrada C, Judith GranadosLópez A, Pérez-Veyna O, Arcos-Ortega T, et al. Hepatoprotective, antihyperlipidemic and radical scavenging activity of hawthorn (Crataegus Oxyacantha) and rosemary (Rosmarinus Officinalis) on alcoholic liver disease. Altern Ther Health Med. 2019; 25: 54-63.

108.Jiang TA. Health benefits of culinary herbs and spices. J AOAC Int. 2019; 102: 395-411. 
109.Eissa FA, Choudhry H, Abdulaal WH, Baothman OA, Zeyadi M, Moselhy SS, et al. Possible hypocholesterolemic effect of ginger and rosemary oils in rats. Afr J Tradit Complement Altern Med. 2017; 14: 188-200.

110.Park MY, Sung MK. Carnosic acid attenuates obesity-induced glucose intolerance and hepatic fat accumulation by modulating genes of lipid metabolism in C57BL/6J-ob/ob mice. J Sci Food Agric. 2015; 95: 828-835.

111.Tu Z, Moss-Pierce T, Ford P, Jiang TA. Rosemary (Rosmarinus officinalis L.) extract regulates glucose and lipid metabolism by activating AMPK and PPAR pathways in HepG2 cells. J Agric Food Chem. 2013; 61: 2803-2810.

112.Ibarra A, Cases J, Roller M, Chiralt-Boix A, Coussaert A, Ripoll C. Carnosic acid-rich rosemary (Rosmarinus officinalis L.) leaf extract limits weight gain and improves cholesterol levels and glycaemia in mice on a high-fat diet. Br J Nutr. 2011; 106: 1182-1189.

113.Park HS, Lee K, Kim SH, Hong MJ, Jeong NJ, Kim MS. Luteolin improves hypercholesterolemia and glucose intolerance through LXR $\alpha$-dependent pathway in diet-induced obese mice. J Food Biochem. 2020; 44: e13358.

114.Abu-Elsaad N, El-Karef A. Protection against nonalcoholic steatohepatitis through targeting IL18 and IL-1alpha by luteolin. Pharmacol Rep. 2019; 71: 688-694.

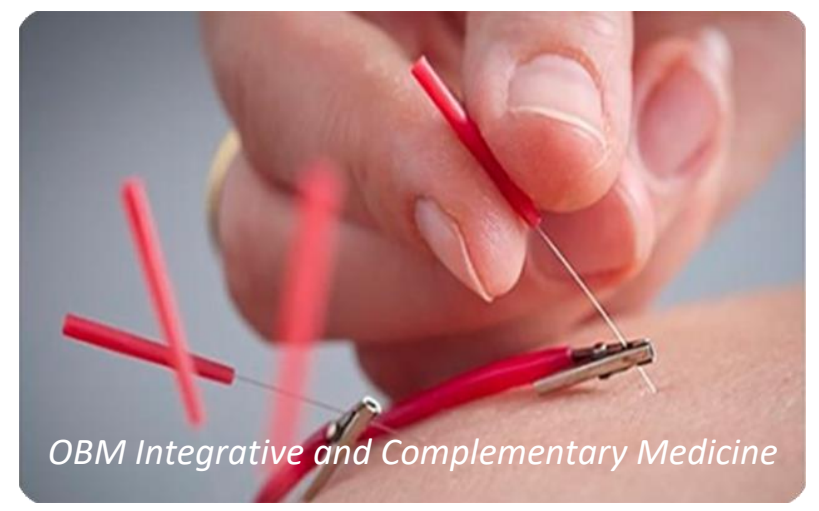

Enjoy OBM Integrative and Complementary Medicine by:

1. Submitting a manuscript

2. Joining in volunteer reviewer bank

3. Joining Editorial Board

4. Guest editing a special issue

For more details, please visit: http://www.lidsen.com/journals/icm 